\title{
Effects of Sematilide, a Novel Class III Antiarrhythmic Agent, on Action Potential in Guinea Pig Atrium
}

\author{
Yasunori Ishii ${ }^{1,2}$, Katsuhiko Muraki ${ }^{1}$, Atsushi Kurihara ${ }^{2}$, Yuji Imaizumi ${ }^{1, *}$ and Minoru Watanabe \\ ${ }^{I}$ Department of Chemical Pharmacology, Faculty of Pharmaceutical Sciences, Nagoya City University, 3-1 Tanabedori, Mizuho-ku, Nagoya 467, Japan \\ ${ }^{2}$ Biology Section, Shirakawa Laboratory, Nippon Roussel, 103-I Ushishimizu, Shirakawa, Fukushima 961, Japan
}

Received October 26, 1994 Accepted March 20, 1995

\begin{abstract}
Electrophysiological effects of sematilide, a novel class III antiarrhythmic agent, were examined and compared with those of ( \pm )sotalol in guinea pig left atrium by a conventional microelectrode technique. Application of $0.1-1000 \mu \mathrm{M}$ sematilide or $1-1000 \mu \mathrm{M}( \pm)$ sotalol concentration-dependently prolonged the duration of action potentials (APD) that were elicited by electrical stimulation at $1 \mathrm{~Hz}$. Other parameters of action potentials such as the maximum upstroke velocity of phase 0 depolarization, action potential amplitude and resting membrane potential were not affected significantly by these drugs in the concentration ranges employed. The prolongation of APD by sematilide or $( \pm)$ sotalol was accompanied by a corresponding increase in the effective refractory period (ERP). Approximately a $30 \%$ increase in ERP was obtained by the treatment with $5 \mu \mathrm{M}$ sematilide or $100 \mu \mathrm{M}( \pm)$ sotalol, suggesting that sematilide as a class III antiarrhythmic agent is approximately 20 times more potent than ( \pm )sotalol on a molecular basis. When the stimulation rate was increased stepwise from 0.2 to $2 \mathrm{~Hz}$, the relative increase in APD at $90 \%$ repolarization by the treatment with sematilide and $( \pm$ )sotalol was slightly larger at $2 \mathrm{~Hz}$ than at $0.2 \mathrm{~Hz}$, indicating that "reverse rate-dependence" was not observed under these conditions. These results may suggest a possibility that sematilide effectively blocks atrial arrhythmia.
\end{abstract}

Keywords: Sematilide, Antiarrhythmic agent (class III), Action potential duration, Frequency-dependence, Atrium (guinea pig)

Antiarrhythmic effects of amiodarone $(1,2)$ and sotalol $(3,4)$ have been related to the prolongation of cardiac action potential duration (APD). Such agents that primarily increase APD and refractoriness have been defined as class III antiarrhythmic compounds (5). Since the increased mortality due to the use of some class Ic antiarrhythmic drugs has been identified in the Cardiac Arrhythmia Suppression Trial (6), class III antiarrhythmic drugs are receiving much interest (see Refs. 7 and $\mathbf{8}$ for reviews). Several new compounds have been derived from $d$-sotalol that lacks $\beta$-adrenergic blocking activity and is considered to be a prototype of a pure class III antiarrhythmic agent (9).

Sematilide hydrochloride ( $N$-[2-(diethylamino)ethyl]-4[(methylsulfonyl)-amino]benzamide $\mathrm{HCl}$ ) is a structural analog to sotalol. The molecular structures of sematilide and $( \pm$ )sotalol are shown in Fig. 1. Both molecules contain the key structural feature of a methanesulfon-

\footnotetext{
* To whom all correspondence should be addressed.
}

anilide group. Sematilide is being evaluated as a class III antiarrhythmic drug in undergoing clinical trials. Previous reports in basic pharmacology have demonstrated that sematilide prolongs APD in some cardiac tissues $(10-14)$. Electrophysiological effects of sematilide in atrial myocytes, however, have not yet been systematically clarified. In the present study, the effects of sematilide were examined and compared with those of $( \pm$ )sotalol in guinea pig atrial myocytes. In addition, it has been reported that several class III agents prolong APD in ventricular myocytes in a reverse frequency-dependent manner. Therefore, rate-dependence of the effects of sematilide and $( \pm)$ sotalol on APD in guinea pig atrial myocytes was also examined in the present study.

\section{MATERIALS AND METHODS}

\section{Measurement of transmembrane potential}

The left atrial preparations were excised from male Hartley guinea pigs (Japan SLC Inc., Hamamatsu) that 

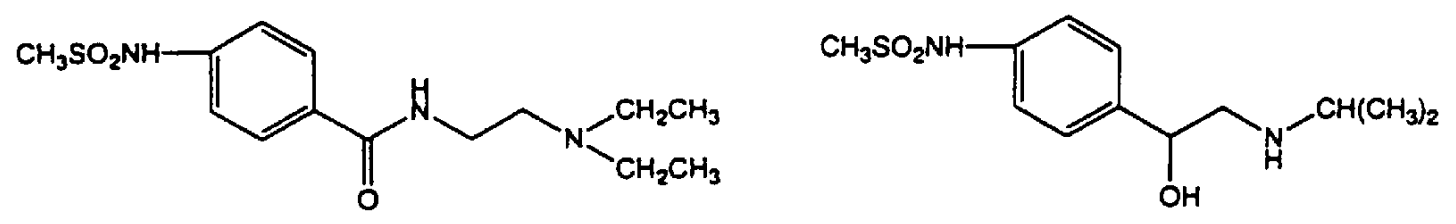

Fig. 1. Chemical structures of sematilide (left) and ( \pm )sotalol (right).

weighed $250-300 \mathrm{~g}$. To avoid the influence of the release of endogenous norepinephrine, animals were treated with reserpine $(3 \mathrm{mg} / \mathrm{kg}$, i.p.) on the day before the experiment. An isolated atrium was cut open, and a small piece of atrial muscle $(2 \times 3 \mathrm{~mm})$ was dissected. The piece of muscle was mounted on a piece of silicon rubber in a 1-ml organ chamber, and this preparation was superfused with Krebs' solution at a rate of 3 to $4 \mathrm{ml} / \mathrm{min}$. Krebs' solution contained $112 \mathrm{mM} \mathrm{NaCl}, 4.7 \mathrm{mM} \mathrm{KCl}, 2.2 \mathrm{mM} \mathrm{CaCl}_{2}$, $1.2 \mathrm{mM} \mathrm{MgCl}_{2}, 25 \mathrm{mM} \mathrm{NaHCO}, 1.2 \mathrm{mM} \mathrm{KH}_{2} \mathrm{PO}_{4}$ and $14 \mathrm{mM}$ glucose. The solution was equilibrated with a mixture of $95 \% \mathrm{O}_{2}$ and $5 \% \mathrm{CO}_{2}$ and was kept at $37 \pm 1^{\circ} \mathrm{C}$. The $\mathrm{pH}$ of the solution was 7.4.

Preparations were electrically stimulated and equilibrated for 30-60 min before drug application. Square pulses of $1 \mathrm{msec}$ in duration at approximately twice the diastolic threshold of action potential generation were applied for electrical stimuli at the basic rate of $1 \mathrm{~Hz}$ through bipolar platinum wire electrodes placed along side of the muscle. The stimuli were generated by an isolator unit (SS-102J; Nihon Kohden, Tokyo) driven by an electronic stimulator (SEN-3201, Nihon Kohden). Transmembrane potential was recorded with conventional glass microelectrodes filled with $3 \mathrm{M} \mathrm{KCl}$ solution. The resistance of these electrodes was between 20 and 40 megaohm in Krebs' solution. The membrane potential was amplified by a high input-impedance amplifier with capacitance neutralization (MEZ-8101, Nihon Kohden) and monitored on a dualbeam memory oscilloscope (VC-10, Nihon Kohden). These electrical signals were recorded on a chart using a pen recorder (FBR-251A; Toa Electronics, Tokyo) and also stored on video tape using a recorder (A-600HF; Toshiba, Tokyo) after being digitized by a PCM-recording system (501ES; Sony, Tokyo; modified to obtain a frequency-response from $\mathrm{DC}$ to $20 \mathrm{kHz}$ ).

\section{Experimental protocols for measurement of action poten-} tials and effective refractory period

When stable recordings of action potentials and the measurement of the effective refractory period (ERP) were obtained after the equilibration for about $60 \mathrm{~min}$, the preparations were treated with a class III antiarrhythmic drug. When several concentrations of a drug were applied, the concentration of the drug in Krebs' solution was increased in a stepwise fashion at intervals of about $30 \mathrm{~min}$. Effects of the drug at a certain concentration were determined from the recordings during the last $10 \mathrm{~min}$ after a 20 -min equilibration.

The frequency dependence of the effect of a drug on APD was examined in preparations stimulated at cycle lengths of 500,1000, 2000 and $5000 \mathrm{msec}$. At each cycle length, the measurement was made after APD reached a steady state.

ERP, defined as the longest interval at which the premature stimulus failed to generate an active response, was determined by applying a single test stimulus at a selected short interval $(5 \mathrm{msec}$ step from 50 to $100 \mathrm{msec}$ interval and $10 \mathrm{msec}$ step from 100 to $200 \mathrm{msec}$ interval) after the 8 th conditioning beat at $1 \mathrm{~Hz}$. The test stimulus was applied at 2 to 3 times threshold in strength by another stimulator (SEN-3301, Nihon Kohden). The procedure for ERP measurement was performed once every $20 \mathrm{sec}$.

\section{Data storage and analysis}

Data were collected from cells having resting membrane potentials more negative than $-75 \mathrm{mV}$ and action potentials greater than $105 \mathrm{mV}$ in peak amplitude. Moreover, only results obtained from stable recordings throughout the experiments were used for data analysis. The data on video tape were replayed later and loaded into a personal computer (IBM-AT) through an A-D converter (DT2801A; Data Translation, Marlborough, MA, USA) for analysis. Data acquisition (AQ; Robinson and Giles, 1986) for the IBM-AT was supplied by Dr. Wayne Giles (Univ. of Calgary, Canada). Action potential parameters were measured by the personal computer using data analysis software (Cellsoft, developed in Dr. Giles' laboratory). Selected records were printed out using a laser printer (Laser Jet Series II; Yokokawa Hewlett Packard, Sagamihara) or plotted by an X-Y plotter (DXY-1300; Roland Digital Group, Hamamastu).

\section{Drugs}

Sematilide and $( \pm$ )sotalol were produced by Berlex Laboratories (Cedar Konlls, NJ, USA) and supplied to Nippon Roussel (Tokyo). These drugs were dissolved in de-ionized water as stock solutions and added by 1:1000 dilution to Krebs' solution to achieve the final concentration desired for superfusion. 


\section{Statistics}

Data are expressed as the mean \pm S.E. in the text, tables and figures. One way analysis of variance (ANOVA) was used for evaluation of the concentration- or frequencydependent changes in action potential parameters. Comparison between two and multiple groups was performed by Student's $t$ - and Scheffe's test, respectively. Statistical significance was indicated by ${ }^{*} \mathrm{P}<0.05,{ }^{* *} \mathrm{P}<0.01$, ${ }^{* * *} \mathrm{P}<0.001$

\section{RESULTS}

\section{Effects of sematilide and ( \pm )sotalol on electrophysiologi- cal parameters of action potentials}

Figure 2 shows typical changes in action potentials in an atrial muscle of the guinea pig with time after application of $10 \mu \mathrm{M}$ sematilide. Action potential duration at $90 \%$ repolarization $\left(\mathrm{APD}_{90}\right)$ gradually increased and achieved a steady state within $20 \mathrm{~min}$. Application of 100 $\mu \mathrm{M}\left( \pm\right.$ )sotalol also induced a similar increase in $\mathrm{APD}_{90}$. Based upon the time course of APD changes, the effects of both drugs were evaluated from the recordings obtained after the effects reached the steady state (after 20 min from the start of drug application; see Materials and Methods for the details). After withdrawal of $10 \mu \mathrm{M}$ sematilide, its effect on $\mathrm{APD}_{90}$ was only partly removed, and that of $100 \mu \mathrm{M}( \pm)$ sotalol was even more difficult to wash away.

The effects of sematilide and $( \pm$ )sotalol on APD were concentration-dependent in the ranges of $0.1-1000 \mu \mathrm{M}$ and $1-1000 \mu \mathrm{M}$, respectively. Figure 3A shows representative recordings in the absence and presence of five different concentrations of sematilide. The increase in APD was observed by application of sematilide from a concentration of $1 \mu \mathrm{M}$ and reached almost a steady level by 1000 $\mu \mathrm{M}$ sematilide. The increase in $\mathrm{APD}_{50}$ was significant in the presence of 100 and $1000 \mu \mathrm{M}$ sematilide (Table 1 , Scheffe's test after one way ANOVA). Figure 3B denotes the relationships between the percent increase in $\mathrm{APD}_{50}$ and concentrations of sematilide or $( \pm)$ sotalol. The increase in $\mathrm{ADP}_{90}$ was significant in the presence of $10 \mu \mathrm{M}$ and higher concentrations of sematilide (Table 1). Figure $3 \mathrm{C}$ shows the relationship for $\mathrm{APD}_{90}$. The increase in APD by $( \pm$ )sotalol did not reach a steady level even at $1000 \mu \mathrm{M}$. Significant increases in $\mathrm{ADP}_{90}$ were observed in the presence of 100 and $1000 \mu \mathrm{M}( \pm$ )sotalol (Table 1). The concentrations of sematilide and $( \pm$ )sotalol that were required for a $30 \%$ increase in $\mathrm{APD}_{90}$ were approximately $10 \mu \mathrm{M}$ and $100 \mu \mathrm{M}$, respectively (Fig. $3 \mathrm{C}$ ), indicating that sematilide is about 10 times more potent than $( \pm)$ sotalol in this respect.

Application of $0.1-1000 \mu \mathrm{M}$ sematilide or $1-1000 \mu \mathrm{M}$ $( \pm)$ sotalol did not affect significantly the resting membrane potential, the action potential amplitude, the

\section{Sematilide $(10 \mu \mathrm{M})$}
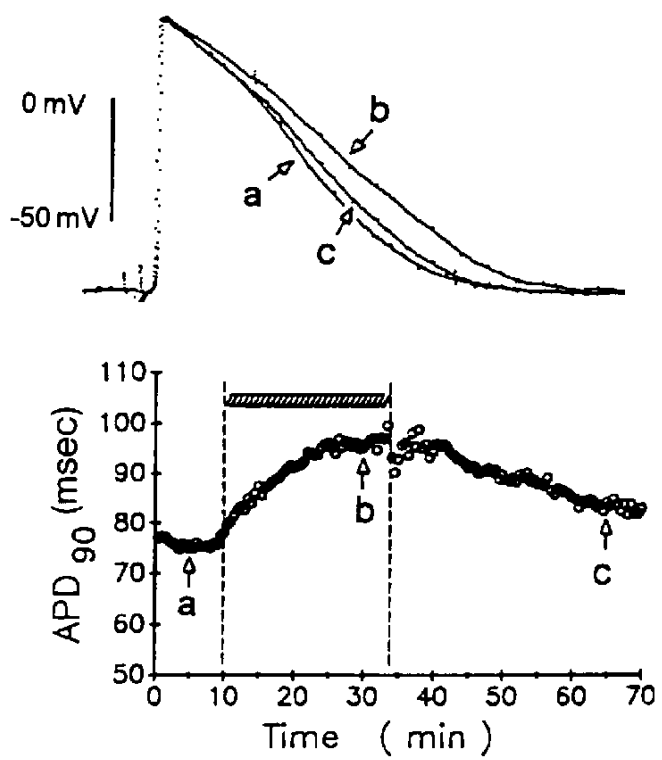

Sotalol $(100 \mu \mathrm{M})$
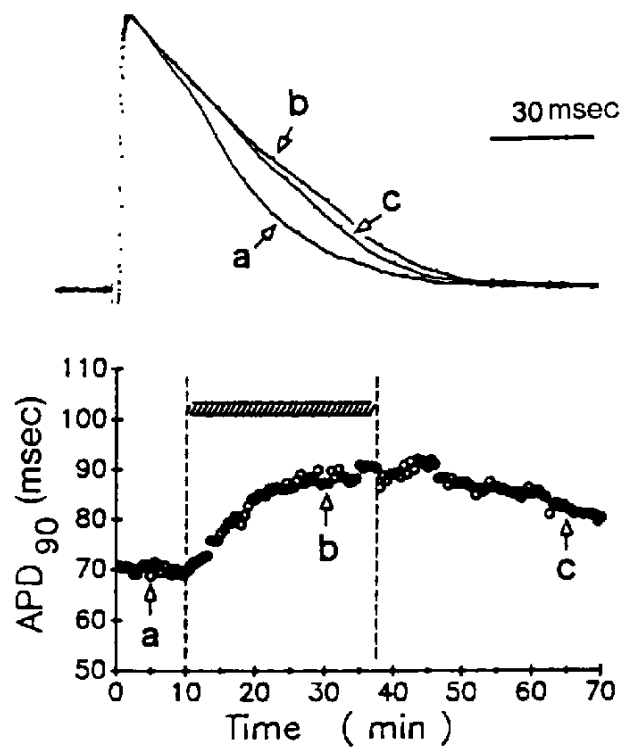

Fig. 2. Effects of $10 \mu \mathrm{M}$ sematilide and $100 \mu \mathrm{M}( \pm)$ sotalol on action potential duration. In the upper panels, three typical records were superimposed, respectively. $a, b$ and $c$ were recorded before and during the application of drugs and after washout, respectively. In lower panels, time course of action potential duration at $90 \%$ repolarization (APD $\mathrm{D}_{90}$ ) after drug application is shown. Drug application was indicated by the horizontal bar. $a, b$ and $c$ in the upper panels were obtained at the corresponding time shown in the time course, respectively. 
A)

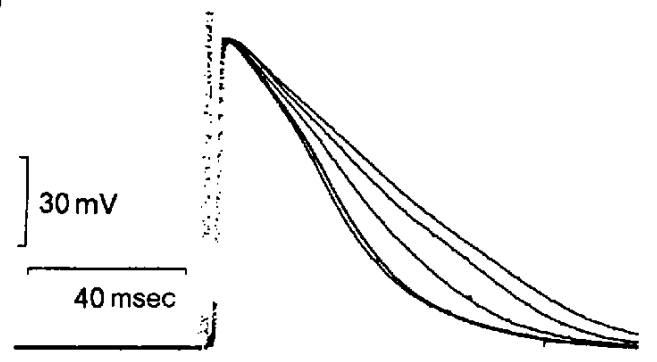

B)

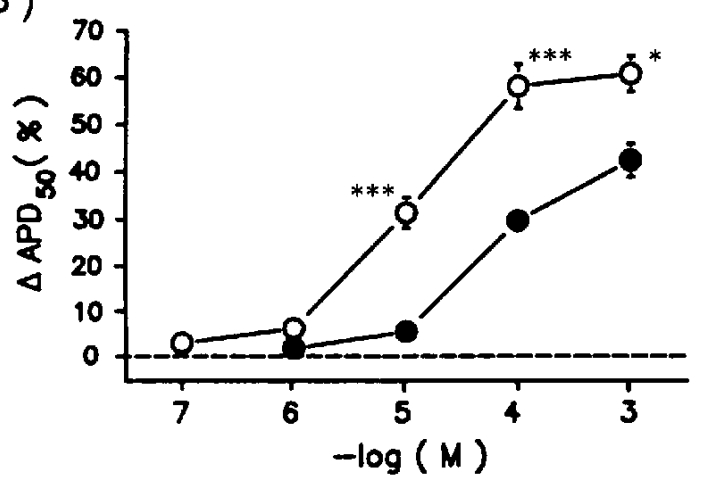

C)

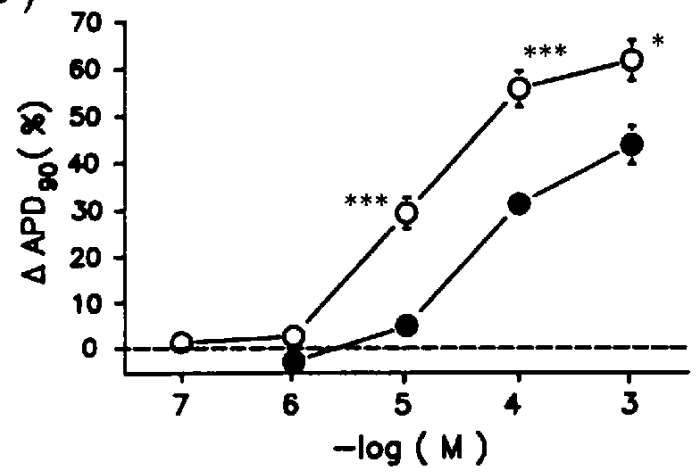

Fig. 3. Concentration-dependent effects of sematilide and $( \pm$ )sotalol on the action potential duration in guinea pig atrium. Preparations were stimulated at $1 \mathrm{~Hz}$. A: Recordings of five action potentials in the absence and presence of four different concentrations of sematilide $(0,1,10,100$ and $1000 \mu \mathrm{M}$; in this order from the left to right in the repolarizing phase) are superimposed. B: Percent changes in action potential duration at $50 \%$ repolarization $\left(\mathrm{APD}_{50}\right)$ are plotted against concentrations of sematilide and $( \pm)$ sotalol. C: Percent changes in $\mathrm{APD}_{90}$ are plotted against concentrations of sematilide and $( \pm$ )sotalol. A symbol and a vertical bar indicate the mean and S.E., respectively. Open and closed circles indicate sematilide $(n=7)$ and $( \pm)$ sotalol $(n=6)$, respectively. Sematilide and $\left( \pm\right.$ )sotalol significantly prolonged $\mathrm{APD}_{50}$ at concentrations higher than $10 \mu \mathrm{M}$ and $\mathrm{APD}_{90}$ at concentrations higher than 1 and $10 \mu \mathrm{M}$, respectively (not indicated in the figure, See Table 1). Effect of sematilide on APD was significantly larger than that of $( \pm)$ sotalol at each concentration in a range of $10\left({ }^{* * *} \mathrm{P}<0.001\right), 100$ $\left({ }^{* * *} \mathrm{P}<0.001\right)$ and $1000 \mu \mathrm{M}\left({ }^{*} \mathrm{P}<0.05\right)$ (Student's $t$-test).
$\mathrm{dV} / \mathrm{dt}_{\max }$ (maximum upstroke velocity of phase 0 depolarization) and $\mathrm{APD}_{20}$, as summarized in Table 1. In this study, changes in action potential shape such as early afterdepolarizations or other forms indicating cellular toxicity were not observed in the presence of either of the drugs at concentrations up to $1000 \mu \mathrm{M}$. These results indicate that sematilide and $( \pm)$ sotalol selectively changed $\mathrm{APD}_{50}$ and $\mathrm{APD}_{90}$ among these electrophysiological parameters.

\section{Effects of sematilide and $( \pm)$ sotalol on effective refrac-} tory period

Figure 4A demonstrates the measurement of the ERP of action potential and effects of sematilide on it (see Materials and Methods for the details). The increase in $A P D_{90}$ in the presence of sematilide or $( \pm)$ sotalol was accompanied by corresponding increase in the ERP (original recordings for ( \pm )sotalol are not shown in Fig. 4A). ERP was significantly prolonged by sematilide or $( \pm$ )sotalol at concentrations of $10-1000$ and $100-1000$ $\mu \mathrm{M}$, respectively (Table 1 , Scheffé's test after one way ANOVA). The concentration-dependence of the percent increase in ERP induced by sematilide or $( \pm)$ sotalol is summarized in Fig. 4B. According to the relationship, the concentrations of sematilide and $( \pm)$ sotalol required for a 30\% increase in ERP in guinea pig atrium were approximately 5 and $100 \mu \mathrm{M}$, respectively.

\section{Frequency dependent effects of sematilide and ( \pm )sotalol} on action potential duration

Figure 5 shows the frequency dependence of the APD (A) and the effects of sematilide (left panels) or ( \pm )sotalol (right pannels) on the changes in $A P D_{90}$ (B) and $A P D_{50}$ (C) at various frequencies in isolated guinea pig atrial muscles. In the absence of drugs, the $\mathrm{APD}_{50}$ and $A P D_{90}$ were not significantly affected by the change in stimulation frequency in a range of 0.2 and $2 \mathrm{~Hz}$, whereas there was a tendency for $\mathrm{APD}_{90}$ to decrease with the increase in frequency (Fig. 5A, P>0.05, Scheffé's test after one way ANOVA). It has been reported that the increase in APD by a class III antiarrhythmic agent is reverse rate-dependent, resulting in an attenuation of the effect with the increase in the stimulation rate. In these experiments, however, the increase in stimulation rate resulted in a small but significant enhancement of the percent increase in $\mathrm{APD}_{90}$ produced by sematilide (B, left) and ( \pm )sotalol ( $B$, right). In contrast, significant frequency dependence of the increase in $\mathrm{APD}_{50}$ was not observed at any concentration of the drugs as shown in Fig. 5C. 
Table 1. Effects of sematilide and ( \pm )sotalol on electrophysiological parameters of action potentials from guinea pig atrium stimulated at $1 \mathrm{~Hz}$

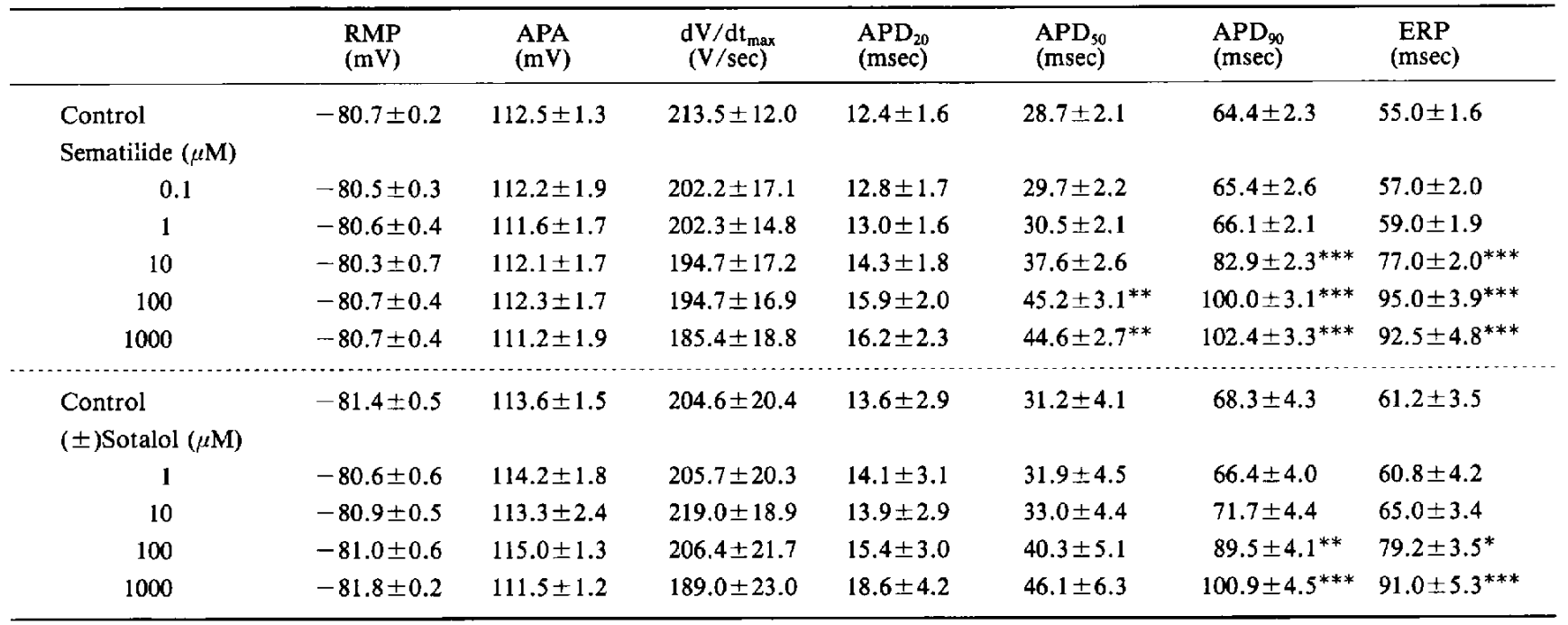

Values are means \pm S.E. of 5-7 experiments. RMP; resting membrane potential; APA: action potential amplitude; $\mathrm{dV} / \mathrm{dt}_{\mathrm{max}}$ : maximum rate of depolarization; $\mathrm{APD}_{20,50}$ and 90 : action potential duration at 20,50 and 90 percent repolarization, respectively; ERP: effective refractory period. ${ }^{*} \mathrm{P}<0.05,{ }^{* *} \mathrm{P}<0.01,{ }^{* * *} \mathrm{P}<0.001$ : ANOVA with Scheffe's test for differences in comparison with the corresponding control values before drug treatment.

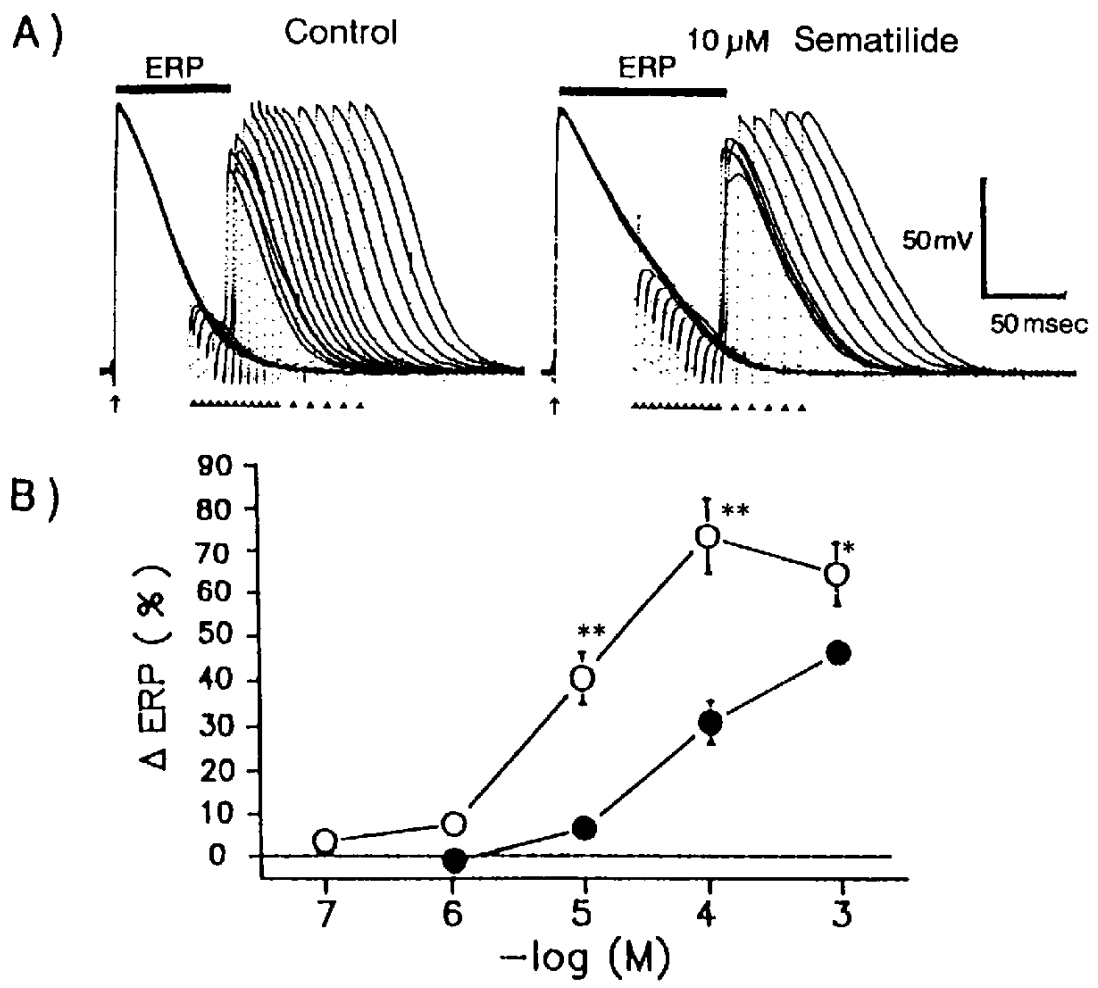

Fig. 4. Effects of sematilide and $( \pm$ )sotalol on effective refractory period (ERP). A: Original traces measuring ERP of the action potential in guinea pig atrium. Sixteen traces were superimposed in each panel. An arrow indicates application of the last stimulus of conditioning train pulses (eight pulses at $1 \mathrm{~Hz}$ ). A closed triangle denotes application of a stimulus with altered interpulse duration from the last conditioning pulse. A horizontal bar indicates ERP which was measured as the period of the shortest interpulse duration that allowed to elicit an action potential. See Materials and Methods for details. B: Percent changes in ERP were plotted against concentrations of sematilide or $( \pm)$ sotalol. Open and closed circles indicate mean values of ERP in the presence of sematilide $(n=5)$ and $( \pm$ )sotalol $(n=6)$, respectively. ERP recorded before the application of sematilide or $( \pm$ )sotalol was $55.0 \pm 1.6$ and $61.2 \pm 3.5 \mathrm{msec}(\mathrm{P}>0.05)$, respectively. Sematilide and $( \pm)$ sotalol significantly prolonged ERP at concentrations higher than 1 and $10 \mu \mathrm{M}$, respectively (not indicated in the figure; See Table 1). Effect of sematilide on ERP was significantly larger than that of $( \pm)$ sotalol at each concentration in a range of $10\left({ }^{* *} \mathrm{P}<0.01\right), 100\left({ }^{* *} \mathrm{P}<0.01\right)$ and $1000 \mu \mathrm{M}$ $\left({ }^{*} \mathrm{P}<0.05\right)$ (Student's $t$-test). 
A)

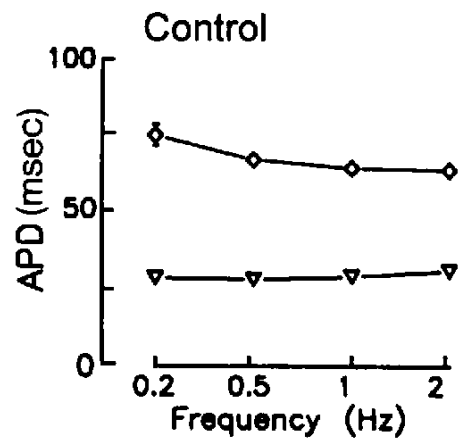

B)

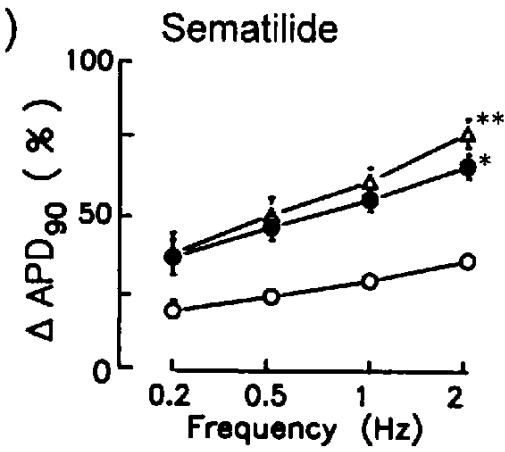

C)

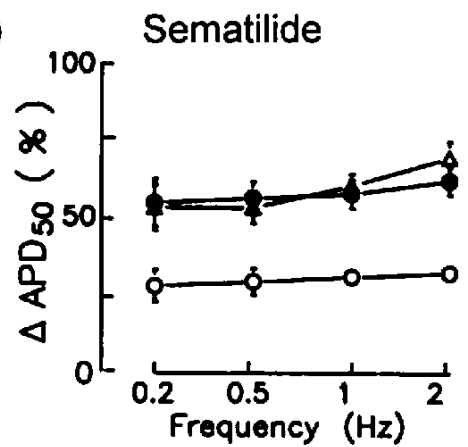

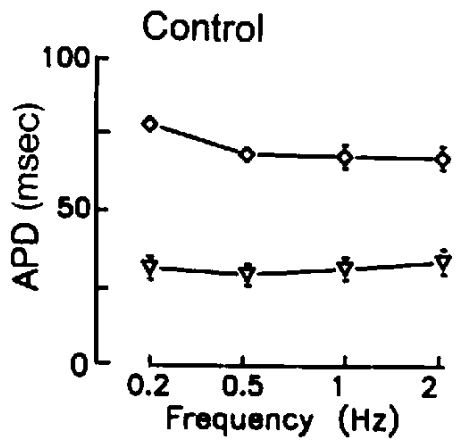
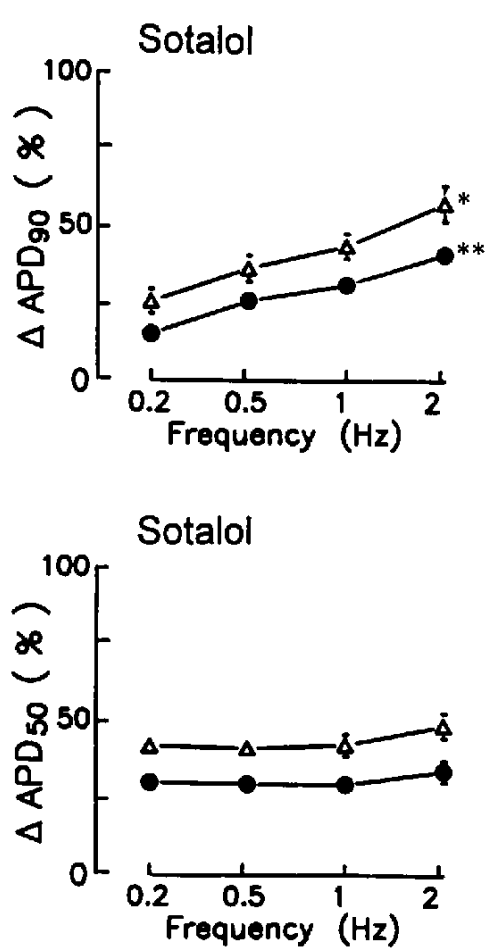

Fig. 5. Rate-dependent effects of sematilide and ( \pm )sotalol on $A_{P D}$ and $A P D_{90}$. A: $A P D_{50}(\nabla)$ and $A P D_{90}(\bigcirc)$ were not significantly affected by changes in stimulation frequency in a range of 0.2 and $2 \mathrm{~Hz}$ under control conditions $(P>0.05$, Scheffé's test after one way ANOVA). Data shown in the left and right panels were obtained under the same conditions but from the cells treated later with sematilide and sotalol, respectively. B and C: Percentage increases in APD 90 and APD D $_{50}$ by sematilide (left) or $( \pm)$ sotalol (right) at various stimulation rates, respectively. Values are the means of 7 and 6 preparations for sematilide and $( \pm$ )sotalol, respectively. Statistical significance was determined between $0.2 \mathrm{~Hz}$ and higher rates (Scheffé's test after one way ANOVA). The percent increase in $\mathrm{APD}_{90}$ by $100 \mu \mathrm{M}$ and $1 \mathrm{mM}$ sematilide (left) or ( \pm )sotalol (right) was significantly larger at 2 $\mathrm{Hz}$ than at $0.2 \mathrm{~Hz}\left({ }^{*} \mathrm{P}<0.05\right.$ or $\left.{ }^{* *} \mathrm{P}<0.01\right)$. Sematilide: $\triangle, 1 \mathrm{mM} ; 0,100 \mu \mathrm{M} ; \bigcirc, 10 \mu \mathrm{M}$. ( \pm )Sotalol: $\triangle, 1 \mathrm{mM} ; \bigcirc, 100 \mu \mathrm{M}$.

\section{DISCUSSION}

The present study clearly demonstrated that sematilide selectively increased APD in a similar manner as $( \pm)$ sotalol did in atrial muscle of the guinea pig heart. It is consistent with the previous observations using sematilide in other cardiac preparations $(10-14)$. The finding that $1000 \mu \mathrm{M}$ sematilide did not affect $\mathrm{dV} / \mathrm{dt}_{\max }$ indicates that it does not block sodium channels. These data are consistent with the fact that methanesulfonanilide class III antiarrhythmic drugs selectively block delayed rectifier type $\mathrm{K}$ current $\left(I_{k}\right)$ that is responsible for action potential repolarization (phase III) $(8,9,15,16)$. Therefore, sematilide is suggested to act as a selective class III antiarrhythmic agent in the atrial muscle of the guinea pig. It is also suggested that the potency of sematilide as a class III antiarrhythmic drug is approximately 20 times higher than that of $( \pm)$ sotalol in terms of the concentrations required for a $30 \%$ increase in ERP.

It has been reported that the effect on APD of several class III drugs exhibits reverse rate-dependence (reverse use-dependence), i.e., greater prolongation of APD at 
longer cycle length $(14,17-19)$, whereas the class Ic antiarrhythmic drug flecainide rate-dependently prolongs atrial action potential $(20)$. Indeed, sematilide also exhibited a reverse use-dependent effect on APD in ventricular muscles (14). In contrast to previous studies, the percent increases in $A P D_{90}$ by both sematilide and $( \pm$ )sotalol were significantly enhanced when the stimulation rate was increased from 0.2 to $2 \mathrm{~Hz}$ in guinea pig atrial muscle. This may be due to a tissue difference in the heart, i.e., atrial and ventricle muscles. It is known that $I_{k}$ consists of two distinct components: $I_{k r}$, a rapidly activating current that exhibits strong inward rectification and $\mathrm{I}_{\mathrm{ks}}$, a slowly activating current with a modest rectification $(15,16) . I_{k r}$ has been originally identified as a component that is selectively blocked by methanesulfonanilide class III antiarrhythmic agents like E-4031 (15). It has been recently reported that the reverse rate-dependent effect of methanesulfonanilide class III agents reflects the diminished contribution of $I_{k r}$ to the net repolarizing current during rapid pacing (21). Incomplete deactivation of $\mathrm{I}_{\mathrm{ks}}$, during short diastolic intervals increases the contribution of $I_{k s}$ as a repolarizing current, partially offsets the rateindependent block of $\mathrm{I}_{\mathrm{kr}}$ and results in the reverse ratedependence in guinea pig ventricular myocytes. Larger contribution of $I_{k r}$ than that of $I_{k s}$ in action potential repolarization has been suggested in atrial myocytes of the guinea pig heart (16). Moreover, the current density of $\mathrm{I}_{\mathrm{kr}}$ in atrial myocytes is considered to be larger than that in ventricular myocytes. Because of the large contribution of $I_{k r}$, the reverse rate-dependence may not be observed in guinea pig atrial muscle in the present study. Alternatively, sematilide might also reduce $\mathbf{I}_{\mathbf{k s}}$ in addition to $I_{k r}$. Further experiments measuring $I_{k r}$ and $I_{k s}$ in single myocytes are required to elucidate the mechanisms of the rate-dependent effect of sematilide in guinea pig atrial muscle.

It has been reported that early afterdepolarizations (EADs) are evoked by class III antiarrhythmic drugs in the ventricular muscle of the guinea pig $(13,17)$ and the rabbit $(18,22)$. It has been suggested that EADs may lead to torsades de pointes (22) and could be a serious undesirable side effect of class III antiarrhythmic drugs. In the present study, EAD-like change in action potential shape was not evoked by application of sematilide and $( \pm$ )sotalol in the concentration ranges examined in the atrium. Further experiments under conditions such as hypokalemia were not performed in the present study.

In conclusion, sematilide selectively prolongs the late repolarization phase of action potentials and the effective refractory period in guinea pig atrial muscle and may possibly be effective on supraventricular tachyarrhythmias.
Acknowledgments

The authors wish to thank Dr. Wayne Giles (University of Calgary, Canada) for providing the data acquisition and analysis programs for the IBM-AT.

\section{REFERENCES}

1 Northover BJ: Alterations to the electrical activity of atrial muscle isolated from the rat heart, produced by exposure in vitro to amiodarone. Br J Pharmacol 82, 191-197 (1984)

2 Kodama I, Suzuki R, Kamiya $K$, Iwata $H$ and Toyama J: Effects of long-term oral administration of amiodarone on the electromechanical performance of rabbit ventricular muscle. $\mathrm{Br}$ J Pharmacol 107, 502-509 (1992)

3 Carmeliet E: Electrophysiologic and voltage clamp analysis of the effects of sotalol on isolated cardiac muscle and Purkinje fibers. J Pharmacol Exp Ther 232, 817-825 (1985)

4 Hafner D, Berger F, Borchard U, Kullmann A and Scherlitz A: Electrophysiological characterization of the class III activity of sotalol and its enantiomers. Arzneimittelforschung 38, $231-236$ (1988)

5 Vaughan Williams EM: Electrophysiological basis for a rational approach to antiarrhythmic drug therapy. In Advances in Drug Research, Edited by Harper NJ and Simmonds AB, pp 69-101, Academic Press, New York (1974)

6 CAST Investigators: Preliminary report: effects of encainide and frecainide on mortality in randomized trial of arrhythmia suppression after myocardial infarction. $N$ Engl J Med 321, 406-412 (1989)

7 Woosley RL: Antiarrhythmic drugs. Annu Rev Pharmacol Toxicol 31, 427-455 (1991)

8 Sanguinetti MC: Modulation of potassium channels by antiarrhythmic and antihypertensive drugs. Hypertension 19, $228-236$ (1992)

9 Hondeghem LM: Development of class III antiarrhythmic agents. J Cardiovasc Pharmacol 20, S17-S22 (1992)

10 Lumma WC, Wohl RA, Davey DD, Argentieri TM, DeVita RJ, Gomez RP, Jain VK, Marisca AJ, Morgan TK, Reiser HJ, Sullivan ME, Wiggins $J$ and Wong SS: Rational design of 4-[(methylsulfonyl)-amino]benzamides as class III antiarrhythmic agents. J Med Chem 30, 756-758 (1987)

11 Morgan TK, Lis R and Lumma WC: Synthesis and cardiac electrophysiological activity of $\mathrm{N}$-substituted-4-( $1 \mathrm{H}$-imidazol-1yl)benzamides - new selective class III agents. J Med Chem 33, $1091-1097$ (1990)

12 Argentieri TM, Carroll MS and Sullivan ME: Cellular electrophysiological effects of the class III antiarrhythmic agents sematilide and clofilium on rabbit atrial tissues. J Cardiovasc Pharmacol 18, 167-174 (1991)

13 Lee KS, Tsai TD and Lee EW: Membrane activity of class III antiarrhythmic compounds; a comparison between ibutilide, $d$-sotalol, sematilide and dofetilide. Eur $\mathrm{J}$ Pharmacol 234, $43-53$ (1993)

14 Sager PT, Nademanee K, Antimisiaris M, Pacifico A, Pruitt C, Godfrey R and Singh BN: Antiarrhythmic effects of selective prolongation of refractoriness - electrophysiologic action of sematilide $\mathrm{HCl}$ in humans. Circulation 88, 1072-1082 (1993)

15 Sanguinetti MC and Jurkiewicz NK: Two components of cardiac delayed rectifier $\mathrm{K}^{+}$current: Different sensitivity to block by class III antiarrhythmic agents. J Gen Physiol 96, 
$195-215$ (1990)

16 Sanguinetti MC and Jurkiewicz NK: Delayed rectifier outward $\mathrm{K}^{+}$current is composed of two currents in guinea pig atrial cell. Am J Physiol 260 (Heart Circ Physiol 29), H393-H399 (1991)

17 Tande PM, Bjornstad H, Yang T and Refsum H: Rate-dependent Class III antiarrhythmic action, negative chronotropy, and positive inotropy of a novel $I_{k}$ blocking drug, UK-68,798: potent in guinea pig but no effect in rat myocardium. J Cardiovasc Pharmacol 16, 401-410 (1990)

18 Nakaya $H$, Tohse $N$, Takeda $Y$ and Kanno M: Effects of MS551 , a new class III antiarrhythmic drug, on action potential and membrane currents in rabbit ventricular myocytes. $\mathrm{Br} \mathrm{J}$ Pharmacol 109, 157-163 (1993)

19 Carmeliet E: Use-dependent block of delayed $\mathrm{K}^{+}$current in rabbit ventricular myocytes. Cardiovasc Drugs Ther 7, 599-
604 (1993)

20 Wang $Z$, Pelletier LC, Talajic $M$ and Nattel S: Effects of frecainide and quinidine on human atrial action potentials: Role of rate-dependence and comparison with guinea pig, rabbit and dog tissues. Circulation 82, 274-283 (1990)

21 Jurkiewicz NK and Sunguinetti MC: Rate-dependent prolongation of cardiac action potentials by a methanesulfonanilide class III antiarrhythmic agent: Specific block of rapidly activating delayed rectifier $\mathrm{K}^{+}$current by dofetilide. Circ Res 72, 75-83 (1993)

22 Carlsson L, Almgreen O and Duker G: QTU-Prolongation and torsades de pointes induced by putative class III antiarrhythmic agents in the rabbit: Etiology and interventions. J Cardiovasc Pharmacol 16, 276-285 (1990) 